\title{
Walking on their own legs: unassisted population growth of the agouti Dasyprocta leporina, reintroduced to restore seed dispersal in an Atlantic Forest reserve
}

\author{
Caio Fittipaldi Kenup, Raíssa Sepulvida \\ Catharina Kreischer and Fernando A. S. Fernandez
}

\begin{abstract}
Reintroduction of locally extirpated species is an increasingly popular conservation tool. However, few initiatives focus on the restoration of ecological processes. In addition, many reintroductions fail to conduct post-release monitoring, hampering both assessment of their success and implementation of adaptive management actions. In 2009 a reintroduction effort was initiated to re-establish a population of the red-rumped agouti Dasyprocta leporina, a scatter-hoarding rodent known to be an important disperser of large seeds, with the aim of restoring ecological processes at Tijuca National Park, south-east Brazil. To assess whether this reintroduced population established successfully we monitored it using mark-resighting during November 2013-March 2015. Population size and survival were estimated using a robust design Poisson-log normal mixed-effects mark-resight model. By March 2015 the number of wild-born individuals fluctuated around 30 and overall growth of the population was positive. As the reintroduced population is capable of unassisted growth, we conclude that the reintroduction has been successful in the medium term. We recommend the cessation of releases, with efforts redirected to continued monitoring, investigation and management of possible threats to the species' persistence, and to quantification of the re-establishment of ecological processes. Reintroduction of $D$. leporina populations can be a cost-effective tool to restore ecological processes, especially seed dispersal, in Neotropical forests.
\end{abstract}

Keywords Agouti, Atlantic Forest, Brazil, demography, population growth, reintroduction success, seed dispersal, wildlife management

Supplementary material for this article can be found at https://doi.org/10.1017/So030605316001149

Caio Fittipaldi Kenup (Corresponding author), Raíssa Sepulvida, Catharina Kreischer and Fernando A. S. Fernandez Laboratory of Ecology and Conservation of Populations, Department of Ecology, Universidade Federal do Rio de Janeiro, Rio de Janeiro, Brazil. E-mail caio.kenup@gmail.com

Received 23 June 2016. Revision requested 4 August 2016.

Accepted 6 September 2016. First published online 15 February 2017.

\section{Introduction}

$\mathrm{O}$ ne of the major consequences of the current biodiversity crisis is defaunation, the local loss or decline of medium- and large-sized vertebrates (Dirzo et al., 2014). Local extinctions of large frugivores are common (e.g. Canale et al., 2012), leading to changes in seed dispersal and predation (Asquith et al., 1999; Galetti et al., 2015), which compromise the structure and diversity of plant communities in tropical forests (Janzen, 1970; Connell, 1971). Such changes in community structure may ultimately affect global ecosystem services such as carbon storage through the replacement of late-successional, dense wooded species by early-successional, rarer ones (Bello et al., 2015).

Reintroductions aim to restore populations in places where they were historically extinct (IUCN/SSC, 2013). By restoring populations of large vertebrates the process of defaunation can be effectively reversed (Oliveira-Santos \& Fernandez, 2010; Seddon et al., 2014). However, reintroduction efforts have a low success rate, and unmonitored releases do little to shed light on the causes of either failure or success (Fischer \& Lindenmayer, 2000). Because knowledge about reintroduced populations is imperfect, management decisions must be made in the face of uncertainty (Armstrong \& Seddon, 2008). Consequently, monitoring should be designed to fill gaps in ecological knowledge to assess reintroduction success and compare the value of alternative management options (Nichols \& Armstrong, 2012). Population monitoring and the estimation of parameters such as abundance, survival and fecundity are paramount to ascertain the fulfilment of demographic criteria of success (Sarrazin, 2007; Converse et al., 2013).

Historically, the main focus of reintroductions has been the recovery of threatened species. Efforts directed at restoring ecological processes are still scarce (Polak \& Saltz, 2011). Nevertheless, it has been argued that the scope of reintroduction biology should be broadened to encompass questions about effects on ecosystem processes (e.g. Lipsey \& Child, 2007; Armstrong \& Seddon, 2008). Defaunated areas benefit from initiatives that aim not only to recover extirpated populations but also to bring back interactions and processes lost with them (Oliveira-Santos \& Fernandez, 2010). Agoutis Dasyprocta spp. are arguably the most efficient dispersers of large seeds in Neotropical forests. Their 
scatter-hoarding behaviour enhances seed dispersal and recruitment of large-seeded plants (Asquith et al., 1999; Pires \& Galetti, 2012), including threatened taxa such as the Critically Endangered Vouacapoua americana (Forget, 1990; Varty \& Guadagnin, 1998). The disperser role Dasyprocta plays goes even further; Dasyprocta punctata individuals are able to locate, steal and relocate seed caches of other individuals, increasing the dispersal distance (Jansen et al., 2012). Furthermore, this competition drives D. punctata to use caches far from the parental trees (Hirsch et al., 2012), which increases the seed germination rate (Carson et al., 2008). Moreover, Dasyprocta spp. tend to cache large seeds more frequently and over longer distances (Galetti et al., 2010) than smaller ones, potentially increasing carbon storage in defaunated areas.

A programme was initiated in 2010 to reintroduce the red-rumped agouti Dasyprocta leporina in Tijuca National Park, an impoverished Atlantic Forest reserve in the city of Rio de Janeiro, Brazil. The goal was to restore the recruitment of large-seeded plants by re-establishing a selfsustaining population of $D$. leporina (Cid et al., 2014), a large rodent, weighing 3-6 kg, whose diet consists mainly of seeds and fruits (Reis et al., 2006). Since 2013 we have monitored the reintroduced population through live capture and camera-trapping, estimating demographic parameters such as abundance, survival rate and recruitment. The monitoring is ongoing but we report here the results up to March 2015, with the main goal of assessing the success of the reintroduction through monitoring of population growth, thereby evaluating the need for further releases or alternative management actions. We also aimed to identify threats to the long-term persistence of the population, as well as to direct future monitoring to provide useful information for its adaptive management.

\section{Study area}

The area now occupied by Tijuca National Park (3,953 ha; Fig. 1) was used mostly for coffee farming up to the 19th century; it was then reforested, with the intent of restoring the degraded water supplies of Rio de Janeiro city (Pádua, 2002). Despite the reforestation many animal species are absent, including important seed dispersers such as the lowland tapir Tapirus terrestris and the woolly spider monkey Brachyteles arachnoides.

Prior to the beginning of our project $D$. leporina, which is categorized as Least Concern on the IUCN Red List (Emmonds \& Reid, 2016), had not been recorded in the Park for at least 2 decades, despite release efforts in the 1970s (Coimbra-Filho et al., 1973). Thirty-one adults were released in the Park during 2010-2014, in a mixed regimen of hard and soft releases (see Supplementary Table $S_{1}$ for information on all individuals released). Previously the

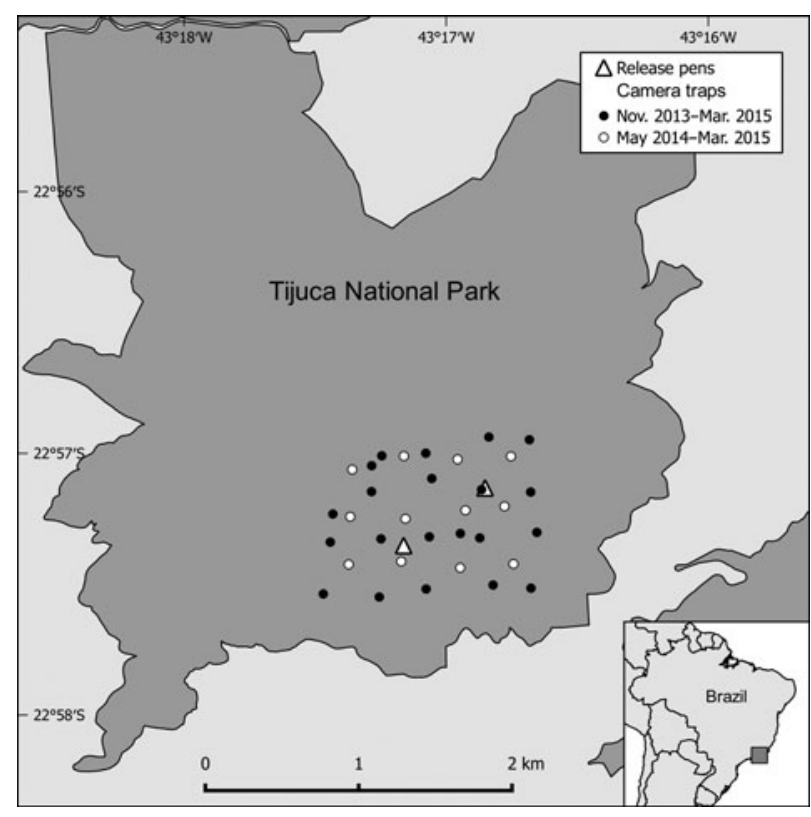

FIg. 1 Location of camera traps and release pens in Tijuca National Park, Brazil. The minimum convex polygon of the camera trap grid is 133.43 ha.

animals had lived in semi-captivity at two urban parks in Rio de Janeiro city. Cid et al. (2014) reported the short-term success of the release effort. The reintroduction reestablished lost ecological interactions to some extent, through dispersal and caching of palm seeds (Zucaratto, 2013).

\section{Methods}

\section{Capture and marking}

We conducted seven capture sessions from July 2013 to March 2015 (Supplementary Table S2). All individuals captured were handled by veterinarians and sedated using a ketamine-midazolam solution. Adults were fitted with coloured plastic collars. We also marked the fur with individual codes of dots and bars, using two techniques: freeze-branding and fur bleaching. Freeze-branding consisted of cooling an aluminium branding iron in dry ice and 90\% alcohol solution, and then applying it to the agouti's shaved skin for 70 seconds. This procedure kills the melanocytes on the epidermis, making the fur grow permanently white (Hadow, 1972). We believe the combination of the two techniques is useful for camera-trapping studies of mammals because (a) the codes are readable at a distance, (b) they may be identified in black \& white photographs (many camera trap models use infrared light instead of flash in low-light environments) and (c) they are complementary: fur bleaching is temporary but immediate, whereas 


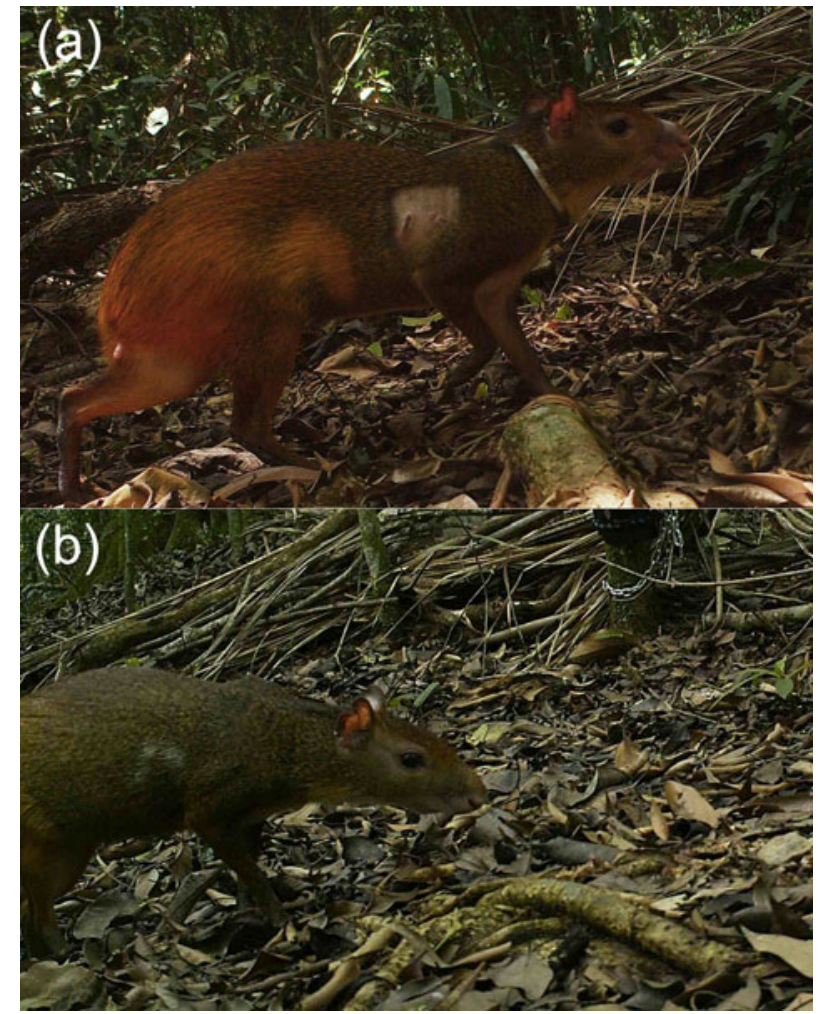

Plate 1 Comparison of fur bleaching and freeze-branding techniques. (a) An adult female agouti Dasyprocta leporina 10 days after marking. Bleached fur is still clearly visible but freeze-branding is not visible. (b) The same individual 404 days after marking. Bleached fur has moulted but the mark made by freeze-branding is visible.

freeze-branding is permanent but requires months to reach readability (Plate 1$)$.

\section{Resighting surveys}

Resighting surveys were carried out using camera trapping after each capture session, from November 2013 onwards. We used a single camera trap (Bushnell Outdoor Products, Overland Park, USA; Tigrinus Equipamentos para Pesquisa, Timbó, Brazil) per station during most surveys, because agoutis were marked on both sides. Traps were checked and baited with sweet potato every 6 days for a total of 30 days per survey. Trap failure events were recorded to track the variation in sampling effort (Foster \& Harmsen, 2012).

We used 21 stations during the first two surveys, and 33 thereafter. The additional stations were deployed within the original grid, increasing resighting effort without changing the area surveyed (Fig. 1). We accounted for effort disparity by considering absent stations as trap failures. Trap spacing was always smaller than the lower confidence limit of home range diameters in the study area (351 m; Cid et al., 2014); thus all individuals in the grid were subject to detection (Foster \& Harmsen, 2012).

\section{Data analysis}

Photographic records were identified at the individual level, or as unmarked when there were no marks on the animal. When there were visible marks but the individual could not be identified with certainty the record was defined as marked but unidentified. Records for which it was not possible to determine the presence or absence of marks were defined as unidentifiable and discarded from the analysis, providing information only on the rate of record loss. Resightings of the same individual were considered to be independent when they were at least 1 hour apart or from different stations. Using different time thresholds for independence did not affect our results (Supplementary Fig. S1). Independent records were pooled for each 6-day interval. Following Armstrong \& Reynolds (2012), we excluded records from the first 45 days after release, to separate survival in the wild from post-release survival.

We used the robust design Poisson-log normal mixed-effects mark-resight model of McClintock \& White (2009) to estimate the number of unmarked individuals $U$ and apparent survival $\phi$ (the complement of the sum of mortality and permanent emigration). Other parameters estimated by this model are $\alpha$ (intercept for mean resighting rate, on the log scale), $\sigma$ (individual heterogeneity in detection rate, on the $\log$ scale), $\gamma^{\prime \prime}$ (probability of temporarily moving out of the study area) and $\gamma^{\prime}$ (probability of remaining outside the study area). The model assumes (a) population closure within each primary sampling interval, (b) no loss of marks within each primary interval, (c) perfect distinction between marked and unmarked individuals, and (d) independently and identically distributed resighting probabilities for marked and unmarked individuals.

Sampling effort and identifiability were not constant throughout the study. We sought to account for this variability with two covariates, which should influence resighting rates: sampling effort (i.e. the sum of all camera trap days over each 6-day interval) and record loss (i.e. the proportion of unidentifiable records over the same period). We used the spatial heterogeneity (variance between camera trap stations) of these variables as a covariate for heterogeneity in detection.

We considered the population to be biologically closed throughout each resighting survey, based on a priori analyses (Supplementary Table $S_{3}$ ). As the model estimates six parameters simultaneously, the potential number of models can be large. We therefore used a stepwise approach to model selection. We began modelling $\alpha$ while keeping all other parameters except $U$ constant, and used only the best models (those with $\triangle \mathrm{AICc}<2$ ) for estimation of a subsequent parameter, then repeated the same process for $\sigma, \phi$, $\gamma^{\prime \prime}$ and $\gamma^{\prime}$, in that order. Covariates used in parameter modelling were origin, age, sex, 6-day interval, resighting survey, sampling effort, spatial variance of sampling effort, record loss and spatial variance of record loss (Table 1 ). 
TABLE 1 Description of covariates used in Poisson-log normal mixed-effects mark-resight models, with the estimated parameters for each model.

\begin{tabular}{|c|c|c|c|c|c|c|c|}
\hline \multirow[b]{2}{*}{ Variable } & \multirow[b]{2}{*}{ Notation } & \multirow[b]{2}{*}{ Description } & \multicolumn{5}{|c|}{ Parameter ${ }^{1}$} \\
\hline & & & $\alpha$ & $\sigma^{2}$ & $\phi$ & $\gamma^{3}$ & $U$ \\
\hline Constant & (.) & Models without any covariate effect & $\mathrm{x}$ & $\mathrm{x}$ & $\mathrm{x}$ & $\mathrm{x}$ & \\
\hline Fixed as 0 & $(0)$ & Models without any covariate effect; parameter fixed as 0 & & $\mathrm{x}$ & & $\mathrm{x}$ & \\
\hline Survey & $(s u r v)$ & A categorical temporal covariate: the resighting survey of the parameters & $\mathrm{x}$ & $\mathrm{x}$ & $\mathrm{x}$ & $\mathrm{x}$ & $\mathrm{x}$ \\
\hline Interval (6 days) & (time) & A categorical temporal covariate: the 6-day interval of the parameter & $\mathrm{x}$ & $\mathrm{x}$ & & & \\
\hline Age & $($ age $)$ & A binary individual covariate: adult $\times$ young & $\mathrm{x}$ & & $\mathrm{x}$ & & \\
\hline Sex & $(\operatorname{sex})$ & A binary individual covariate: female $\times$ male & $\mathrm{x}$ & & $\mathrm{x}$ & & \\
\hline Captivity & $(c a p t v)$ & A binary individual covariate: captive $\times$ wild-born & $\mathrm{x}$ & & $\mathrm{x}$ & & \\
\hline Sampling effort & $(e f f)$ & A continuous temporal covariate: effort in camera-trap days over a 6-day interval & $\mathrm{x}$ & & & & \\
\hline Record loss & (rloss) & A continuous temporal covariate: the rate of discarded records over a 6-day interval & $\mathrm{x}$ & & & & \\
\hline Effort variance & (eff var) & $\begin{array}{l}\text { A continuous temporal covariate: the variance of }(\mathrm{eff}) \text {, calculated over all trapping } \\
\text { stations for each 6-day interval }\end{array}$ & & $\mathrm{x}$ & & & \\
\hline $\begin{array}{l}\text { Record loss } \\
\text { variance }\end{array}$ & $\begin{array}{l}\text { (rloss } \\
\text { var })\end{array}$ & $\begin{array}{l}\text { A continuous temporal covariate: the variance of (rloss), calculated over all trapping } \\
\text { stations for each 6-day interval }\end{array}$ & & $\mathrm{x}$ & & & \\
\hline
\end{tabular}

${ }^{1} \alpha$, intercept on the log scale of the resighting rate; $\sigma$, variation in resighting rate as a result of individual heterogeneity; $\phi$, apparent survival; $\gamma^{\prime \prime}$, probability of temporarily emigrating out of the study area; $\gamma^{\prime}$, probability of remaining outside of the study area; $U$, number of unmarked individuals in the population. ${ }^{2} \sigma$ was a function of eff var or rloss var in models that had an effect of eff or rloss on $\alpha$.

${ }^{3} \gamma^{\prime \prime}$ and $\gamma^{\prime}$ are presented together as they were always modelled as a function of the same covariates.

We used parameter estimates from the model to derive parameters of interest for population management. We used a conservative estimate of $\hat{N}$ by adding the minimum number of marked individuals known alive to the estimated number of unmarked individuals $\hat{U}$. Recruitment was then calculated as

$$
\hat{B}_{t}=\hat{N}_{t}-\left(\hat{N}_{t-1} \times \hat{\phi}_{t}^{*}\right)
$$

where $\hat{\phi}_{t}^{*}$ is uncorrected, or realized, survival (this distinction is important because most estimation packages correct transition parameters for a constant period of time). Population growth was measured by the finite rate of increase, or $\lambda$. An indicator of reintroduction success is $\lambda>_{1}$ (positive growth) without the aid of additional releases (Ostermann et al., 2001). The finite rate of increase over a period $t-1$ to $t$ is calculated as

$$
\hat{\lambda}_{t-1, t}=\frac{\hat{N}_{t}}{\hat{N}_{t-1}}
$$

As $\hat{N}_{t}$ and $\hat{\phi}_{t}^{*}$ are estimated parameters with associated standard errors, we were able to derive standard errors for $\hat{B}_{t}$ and $\hat{\lambda}_{t}$ through parametric bootstrapping, assuming a lognormal distribution for $\hat{N}$ and a normal distribution for $\hat{\phi}^{*}$ on the logit scale (Williams et al., 2002). All analyses were conducted in $R$ v.3.3.1 (R Development Core Team, 2016), using the package RMark to interface with MARK (White \& Burnham, 1999), and the source code for all analyses is available at https://doi.org/10.5281/zenodo.202290.

\section{Results}

During 428 live-trapping nights we obtained 38 captures of 18 individuals. The number of captures was highest in August 2014 and lowest in November 2014 and March 2015. Half of the individuals captured were young, and this proportion was higher in August 2014 (57.1\%; Supplementary Table S4).

The total sampling effort of resighting surveys was 4,764 trap-days, with a mean of $159 \pm 34$ per interval

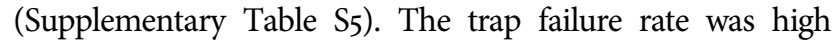
(19.8\%). However, we explicitly incorporated variation in sampling effort when estimating resighting rates, and therefore this variation should not bias our estimates. We obtained 3,719 independent records of agoutis, of which $17.64 \%$ were discarded as unidentifiable (Supplementary Table S6).

After running the stepwise model selection for all parameters, eight models had $\Delta$ AICc $<2$ (Table 2; see Supplementary Tables S7-S10 for a full account of models run). Model-averaged estimates did not differ from the best model, and thus we report here the best-fitting model estimates rather than model-averaged ones. Resighting rate was influenced by effort $\left(\hat{\beta}_{\text {eff }}^{\alpha}=0.003 \pm 0.002\right)$, record loss $\left(\hat{\beta}_{\text {rloss }}^{\alpha}=-3.10 \pm 0.58\right), \quad$ captivity $\left(\hat{\beta}_{\text {captv }}^{\alpha}=0.26 \pm 0.11\right)$ and sex $\left(\hat{\beta}_{\text {sex }}^{\alpha}=0.46 \pm 0.20\right)$. Individual heterogeneity was affected by variance of record loss $\left(\hat{\beta}_{\text {rloss } \text { var }}^{\sigma}=6.50 \pm 3.53\right)$, and survival was influenced by age $\left(\hat{\beta}_{\text {age }}^{\phi}=2.34 \pm 0.97\right)$. Mean apparent survival $\hat{\phi}$ was estimated to be $0.92 \pm 0.04$ for adults and $0.54 \pm 0.20$ for juveniles. Estimated monthly recruitment between surveys was mostly low, with a peak of 8.71 (95\% CI 6.23-11.59) during May-August 2014. Estimated population size of wild individuals was lowest in November 2013 (15.68; 95\% CI 12.7-19.58) and highest in August 2014 (41.6; 95\% CI 37.38-46.46), declining to 29.8 (95\% CI 
TABLE 2 Most likely robust design Poisson-log normal mixed-effects mark-resight models (Table 1). Model selection was conducted in a stepwise manner, modelling each type of parameter separately and keeping the most likely models $(\Delta \mathrm{AICc}<2)$ for the next step. Only models with $\Delta \mathrm{AIC}_{\mathrm{c}}<10$ are shown (see Supplementary Tables $\mathrm{S}_{7}-\mathrm{S}_{10}$ for a full list of models run).

\begin{tabular}{|c|c|c|c|c|c|}
\hline Model $^{*}$ & $k$ & $\mathrm{AICc}$ & $\Delta \mathrm{AICc}$ & $w_{i}$ & Deviance \\
\hline$\alpha_{(e f f+r l o s s+c a p t v+s e x)} \sigma_{(\text {rloss var })} \phi_{(\text {age })} \gamma_{(.)}$ & 17 & $1,083.66$ & 0.00 & 0.200 & $1,045.61$ \\
\hline$\alpha_{(e f f+r l o s s+c a p t v+s e x)} \sigma_{(.)} \phi_{(a g e)} \gamma_{(.)}$ & 16 & $1,084.24$ & 0.58 & 0.149 & $1,048.66$ \\
\hline$\alpha_{(e f f+\text { rloss }+ \text { captv+age+sex })} \sigma_{(.)} \phi_{(\text {age })} \gamma_{(.)}$ & 17 & $1,084.34$ & 0.68 & 0.142 & $1,046.29$ \\
\hline$\alpha_{(e f f+\text { rloss }+ \text { captv+age }+ \text { sex })} \sigma_{(\text {rloss var })} \phi_{(\text {age })} \gamma_{(.)}$ & 18 & $1,084.57$ & 0.91 & 0.127 & $1,044.01$ \\
\hline$\alpha_{(\text {eff }+ \text { rloss }+ \text { captv }+ \text { sex })} \sigma_{(\text {rloss var })} \phi_{(\text {age }+ \text { sex })} \gamma_{(.)}$ & 18 & $1,084.90$ & 1.24 & 0.107 & $1,044.34$ \\
\hline$\alpha_{(e f f+\text { rloss }+ \text { age }+ \text { sex })} \sigma_{(.)} \phi_{(\text {age })} \gamma_{(.)}$ & 16 & $1,085.15$ & 1.49 & 0.095 & $1,049.57$ \\
\hline$\alpha_{(e f f+\text { rloss }+ \text { captv }+ \text { sex })} \sigma_{(.)} \phi_{(\text {age }+ \text { sex })} \gamma_{(.)}$ & 17 & $1,085.45$ & 1.79 & 0.082 & $1,047.39$ \\
\hline$\alpha_{(e f f+\text { rloss }+ \text { captv+age }+ \text { sex })} \sigma_{(.)} \phi_{(\text {age }+ \text { sex })} \gamma_{(.)}$ & 18 & $1,085.58$ & 1.92 & 0.076 & $1,045.02$ \\
\hline$\alpha_{(e f f+r l o s s+\text { captv }+ \text { sex })} \sigma_{(\text {rloss var })} \phi_{(\text {age })} \gamma_{(\text {surv })}$ & 21 & $1,090.96$ & 7.30 & 0.005 & $1,042.67$ \\
\hline$\alpha_{(e f f+\text { rloss }+ \text { capt } v+\text { age }+ \text { sex })} \sigma_{(.)} \phi_{(\text {age })} \gamma_{(\text {surv })}$ & 21 & $1,091.64$ & 7.98 & 0.004 & $1,043.35$ \\
\hline$\alpha_{(\text {eff }+ \text { rloss }+ \text { captv }+ \text { age }+ \text { sex })} \sigma_{(\text {rloss var })} \phi_{(\text {age })} \gamma_{(\text {surv })}$ & 22 & $1,092.00$ & 8.34 & 0.003 & $1,041.07$ \\
\hline$\alpha_{(e f f+r l o s s+a g e+s e x)} \sigma_{(.)} \phi_{(\text {age })} \gamma_{(\text {surv })}$ & 20 & $1,092.31$ & 8.65 & 0.003 & $1,046.63$ \\
\hline$\alpha_{(e f f+r l o s s+c a p t v+s e x)} \sigma_{(\text {rloss var })} \phi_{(\text {age }+ \text { sex })} \gamma_{(\text {surv })}$ & 22 & $1,092.34$ & 8.68 & 0.003 & $1,041.41$ \\
\hline$\alpha_{(e f f+r l o s s+c a p t v+s e x)} \sigma_{(.)} \phi_{(\text {age }+ \text { sex })} \gamma_{(\text {surv })}$ & 21 & $1,092.74$ & 9.08 & 0.002 & $1,044.46$ \\
\hline$\alpha_{(e f f+\text { rloss }+ \text { capt } v+\text { age }+ \text { sex })} \sigma_{(.)} \phi_{(\text {age }+ \text { sex })} \gamma_{(\text {surv })}$ & 22 & $1,093.02$ & 9.36 & 0.002 & $1,042.09$ \\
\hline
\end{tabular}

* Parameter $U$ is omitted because it was always modelled as survey-dependent parameter.

25.55-34.94) in the last survey, in March 2015 (Fig. 2a). The overall finite rate of increase $\hat{\lambda}_{1, t}$ for the whole study period was 1.92 (95\% CI 1.44-2.48).

\section{Discussion}

Age was the main driver of variation in survival rates; adults had higher probabilities of surviving than young individuals. High mortality of juveniles has also been reported for D. punctata on Barro Colorado Island, Panama (Smythe, 1978), where it was mainly attributed to mammalian predators, such as South American coatis Nasua narica and ocelots Leopardus pardalis (Smythe, 1978; Silvius \& Fragoso, 2003). There are no large native mammals in Tijuca National Park that could prey upon adult agoutis (ICMBio, 2008). The abundant coati is a potential predator of young agoutis but we have never observed a coati chasing an agouti; rather, we observed a released agouti foraging alongside a group of coatis. However, we believe a major driver of agouti mortality is predation by domestic dogs Canis lupus familiaris. We repeatedly observed dogs chasing and killing agoutis in the Park.

Release into the wild is often associated with reduced survival, especially when released individuals come from captivity (Jule et al., 2008; Tavecchia et al., 2009). However, we found the opposite: Cid et al. (2014) reported higher post-release survival rates during 2010-2011 (monthly $\hat{\phi}$ : o.98) than those we estimated for adult individuals during 2013-2015. Because population size and density had increased since the time of release, an increase in competition for food could have worsened mean individual body condition and increased intraspecific aggression. Additionally, predation by dogs may have increased since the 2010 releases because individuals residing in the Park could have developed a search image as encounters with $D$. leporina became more frequent (generally speaking, a search image develops when a predator becomes accustomed to a common prey item, and thus becomes more efficient at preying upon it; Ishii \& Shimada, 2010). Furthermore, as we could estimate only apparent survival $\phi$ and not true survival $S$, we cannot distinguish mortality from permanent emigration (Williams et al., 2002). Cid et al. (2014), however, used a known fate model, which could distinguish these confounding rates. Our sampling area is not geographically closed, and therefore low survival may be partially explained by individuals, especially juveniles, dispersing away from the sampling area.

Juveniles were recorded in all surveys. However, the high number of captures of this age group and recruitment in the middle of the year suggest a peak in recruitment. The only recorded decrease in abundance occurred after this peak. Although this decrease is certainly attributable to higher mortality in young individuals, losses must also have been caused by juvenile dispersal. Besides an increase in population size, spatial expansion is also expected in thriving reintroduced populations (Bar-David et al., 2005; MolinariJobin et al., 2010). Larger-scale monitoring is needed to assess population expansion throughout the Park and to distinguish mortality from dispersal.

In total, 31 individuals were released since 2010; 11 died or were removed within 12 weeks of release, and therefore we consider the release group size to be 20 (Supplementary Table S1). By March 2015 numbers of wild-born individuals fluctuated around 30. The number of wild-born individuals had thus surpassed the release group size. Most of the 

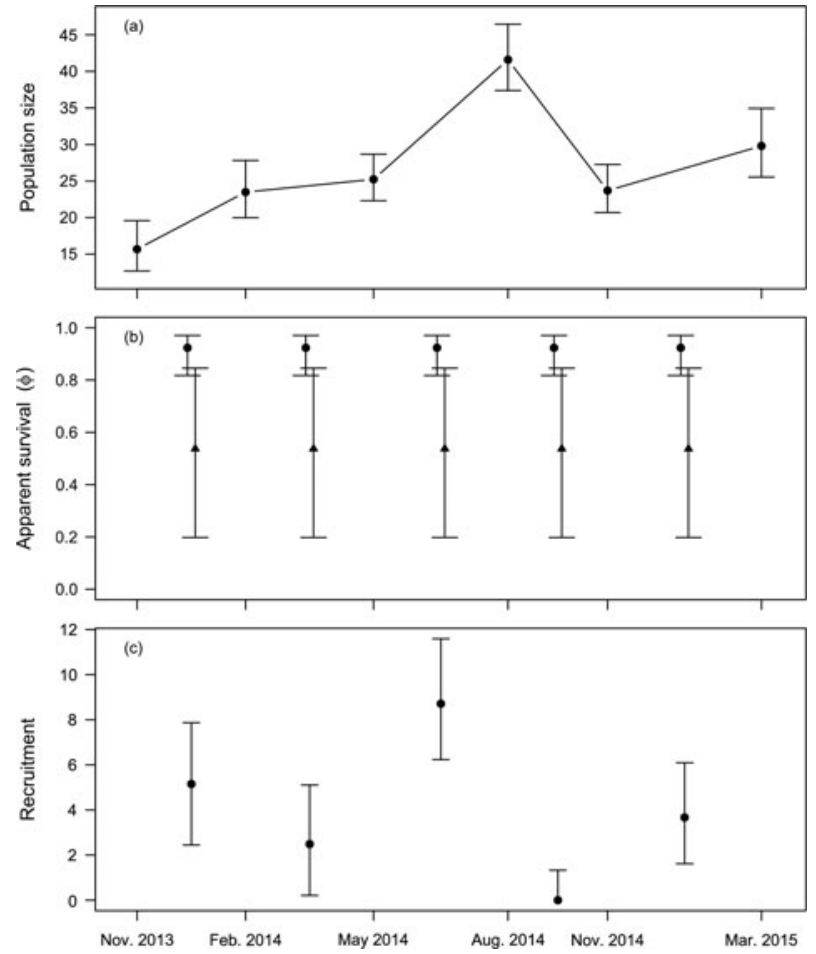

FIG. 2 Demographic parameters of Dasyprocta leporina (mean and $95 \%$ confidence intervals) estimated through markresighting in Tijuca National Park. (a) Population size estimates for each resighting survey. (b) Monthly survival estimates for adult (circles) and young (triangles) animals. (c) Monthly recruitment estimates (because recruitment is zero-truncated, we report the median instead of the mean).

increase was as a result of the reproductive success of the wild population, as we detected only four reintroduced individuals in our monitoring. Besides, our population estimates are likely to be conservative because our sampling grid was not geographically closed and the population had probably already expanded beyond it. Unassisted population increase is a basic criterion for the success of reintroduced populations (Armstrong \& Seddon, 2008) and represents a critical demographic landmark that many reintroductions fail to achieve (Fischer \& Lindenmayer, 2000). The reintroduction of agoutis had been considered to be successful in the short term (Cid et al., 2014), and we conclude that it has also been successful in the medium term, entering the population growth phase as described by Sarrazin (2007). The long-term success can be ascertained only by the onset of population regulation (Sarrazin, 2007), leading to eventual population stability and viability.

We are not aware of what caused the previous reintroduction effort (Coimbra-Filho et al., 1973) to fail, as no postrelease monitoring was undertaken. The number of individuals released was low (25), and thus the release group was vulnerable to demographic stochasticity. Nevertheless, their numbers were not much smaller than ours. The previous releases (Coimbra-Filho et al., 1973) were sparse both in space and time; they were spread across three release sites c. $1 \mathrm{~km}$ apart and individuals were released at a mean rate of 1.5 per month at the site with most releases. In addition, individuals may have been killed by domestic dogs roaming the Park, or by illegal hunters. Even with a positive trend in growth, the same threats may still be present in the Park, and render the agouti population vulnerable to extirpation. Continuous monitoring of the population and further investigation of the drivers of mortality in all age classes are needed to assess the long-term viability of the population.

Despite positive growth overall, the population is still small and thus vulnerable to demographic stochasticity (Caughley, 1994). Additional releases may increase persistence probability and population growth, and decrease the likelihood of bottleneck-induced endogamic depression. On the other hand, during the last 2 years of monitoring the population increased with little aid from additional releases. It is important to assess when releases no longer significantly increase viability (Schaub et al., 2009). At this point financial and logistical resources should be directed to other management actions (such as predator control) or to monitoring programmes that will provide the most useful information for future decision making (Nichols \& Armstrong, 2012).

The main goal of the reintroduction of $D$. leporina in Tijuca National Park is to restore recruitment of large-seeded plants (Cid et al., 2014). Seed burial of Astrocaryum aculeatissimum is conditional on the local presence of $D$. leporina (Zucaratto, 2013); however, the agouti's effect on other plant species has not yet been assessed. Moreover, there is no quantitative information available about the influence of local agouti abundance on the rate of seed burial and dispersal distance. On Barro Colorado Island intraspecific competition in D. punctata increases dispersal distances through cache theft (Jansen et al., 2012), and scatter-hoarding is directed to areas with low conspecific tree densities to avoid such thefts (Hirsch et al., 2012). As the positive effect of these behaviours on seed dispersal should increase with increased density, monitoring $D$. leporina density and its effect on large-seeded plant demography could establish a minimum density threshold as a criterion of success for the goal of restoring ecological interactions (Polak \& Saltz, 2011).

Despite the high failure rate of reintroduction attempts, some projects succeed even with a small number of founders (Taylor et al., 2005; Reynolds et al., 2012). The reintroduction of $D$. leporina was successful in the medium term after the release of only 31 individuals. Thus, $D$. leporina has the potential to achieve high numbers from small release groups. The total annual cost of the reintroduction is USD 6,300 , including releases in the wild and post-release and population monitoring (but excluding personnel salaries; Table S11), which is significantly smaller than costs (up to USD 1,000,000) reported for other reintroductions (Fischer \& Lindenmayer, 2000). Thus the reintroduction 
of $D$. leporina is a cost-effective tool for habitat restoration, given its key role in the enhancement of large-seeded plant recruitment, low reintroduction costs and high likelihood of success. Moreover, long-term monitoring of both demographic and ecosystem processes resulting from these efforts can identify threats to population persistence and drivers of reintroduction success, as well as the impact of agoutis on the plant community through seed consumption and dispersal.

\section{Acknowledgements}

This study received financial support from Conselho Nacional de Desenvolvimento Científico e Tecnológico, Fundação de Amparo à Pesquisa do Estado do Rio de Janeiro, Coordenação de Aperfeiçoamento de Pessoal de Nível Superior and Fundação Grupo Boticário de Proteção à Natureza. The agoutis released were provided by Fundação Parques e Jardins and the administration of Palacete Modesto Leal. Licenses for capture, transport and release were granted by Instituto Chico Mendes de Conservação da Biodiversidade. We thank the staff of Fundação Jardim Zoológico do Rio de Janeiro and our partners at Fundação Oswaldo Cruz for providing veterinary screening and handling support both ex situ and in situ, as well as animal housing pre-release. We are grateful to B. Araujo, A. Arevalo, A. Landim, A.F. Mello, H. Menezes, M. Rheingantz and many others for help in the field, and to two anonymous reviewers for their comments and insights.

\section{Author contributions}

The study was conceived and designed by CFK and FASF. Fieldwork, analysis of photographs and curation of data were organized and conducted by CFK, RS and CK. Data analyses were conducted by CFK, with insights from FASF. All authors contributed to writing the article.

\section{References}

Armstrong, D.P. \& Reynolds, M.H. (2012) Modelling reintroduced populations: the state of the art and future directions. In Reintroduction Biology: Integrating Science and Management (eds J. G. Ewen, D.P. Armstrong, K.A. Parker \& P.J. Seddon), pp. 165-222. Wiley-Blackwell, Oxford, UK.

Armstrong, D.P. \& Seddon, P.J. (2008) Directions in reintroduction biology. Trends in Ecology \& Evolution, 23, 20-25.

Asquith, N.M., Terborgh, J., Arnold, A.E. \& Riveros, C.M. (1999) The fruits the agouti ate: Hymenaea courbaril seed fate when its disperser is absent. Journal of Tropical Ecology, 15, 229-235.

Bar-David, S., Saltz, D. \& Dayan, T. (2005) Predicting the spatial dynamics of a reintroduced population: the Persian fallow deer. Ecological Applications, 15, 1833-1846.

Bello, C., Galetti, M., Pizo, M.A., Magnago, L.F.S., Rocha, M.F., Lima, R.A.F. et al. (2015) Defaunation affects carbon storage in tropical forests. Science Advances, 1, e1501105, https://doi.org/10.1126/ sciadv.1501105.

Canale, G.R., Peres, C.A., Guidorizzi, C.E., Gatto, C.A.F. \& Kierulff, M.C.M. (2012) Pervasive defaunation of forest remnants in a tropical biodiversity hotspot. PLoS ONE, 7(8), e41671.

Carson, W.P., Anderson, J.T., Leigh, Jr, E.G. \& Schnitzer, S.A. (2008) Challenges associated with testing and falsifying the JanzenConnell hypothesis: a review and critique. In Tropical Forest Community Ecology (eds W. Carson \& S. Schnitzer), pp. 210-241. Wiley-Blackwell, Oxford, UK.

Caughley, G. (1994) Directions in conservation biology. Journal of Animal Ecology, 63, 215-244.

Cid, B., Figueira, L., Mello, A.F.T., Pires, A.S. \& Fernandez, F.A. S. (2014) Short-term success in the reintroduction of the red-humped agouti Dasyprocta leporina, an important seed disperser, in a Brazilian Atlantic Forest reserve. Tropical Conservation Science, 7, 796-810.

Coimbra-Filho, A.F., Aldrighi, A.D. \& Martins, H.F. (1973) Nova contribuição ao restabelecimento da fauna do Parque Nacional da Tijuca, GB, Brasil. Brasil Florestal, 4, 7-25.

Connell, J.H. (1971) On the role of natural enemies in preventing competitive exclusion in some marine animals and in the rain forest trees. In Dynamics of Populations (eds P.J. den Boer \& R. Gradwell), pp. 298-310. Centre for Agriculture Publications and Documentation, Wageningen, The Netherlands.

Converse, S.J., Moore, C.T. \& Armstrong, D.P. (2013) Demographics of reintroduced populations: estimation, modeling, and decision analysis. The Journal of Wildife Management, 77, 10811093.

Dirzo, R., Young, H.S., Galetti, M., Ceballos, G., Isaac, N.J.B. \& Collen, B. (2014) Defaunation in the Anthropocene. Science, 345, 401-406.

Emmonds, L. \& Reid, F. (2016) Dasyprocta leporina. The IUCN Red List of Threatened Species 2016: e.T89497102A22197762. Https://doi. org/10.2305/IUCN.UK.2016-2.RLTS.T89497102A22197762.en [accessed 21 November 2016].

Fischer, J. \& Lindenmayer, D.B. (200o) An assessment of the published results of animal relocations. Biological Conservation, 96, $1-11$.

Forget, P.M. (1990) Seed-dispersal of Vouacapoua americana (Caesalpiniaceae) by caviomorph rodents in French Guiana. Journal of Tropical Ecology, 6, 459-468.

Foster, R.J. \& Harmsen, B.J. (2012) A critique of density estimation from camera-trap data. The Journal of Wildlife Management, 76, 224-236.

Galetti, M., Bovendorp, R.S. \& Guevara, R. (2015) Defaunation of large mammals leads to an increase in seed predation in the Atlantic forests. Global Ecology and Conservation, 3, 824-830.

Galetti, M., Donatti, C.I., Steffler, C., Genini, J., Bovendorp, R.S. \& FLEURY, M. (2010) The role of seed mass on the caching decision by agoutis, Dasyprocta leporina (Rodentia: Agoutidae). Zoologia (Curitiba), 27, 472-476.

Hadow, H.H. (1972) Freeze-branding: a permanent marking technique for pigmented mammals. The Journal of Wildlife Management, 36, 645-649.

Hirsch, B.T., Kays, R., Pereira, V.E., Jansen, P.A. \& Rejmanek, M. (2012) Directed seed dispersal towards areas with low conspecific tree density by a scatter-hoarding rodent. Ecology Letters, 15 , 1423-1429.

iCMBio (Instituto Chico Mendes de Conservação da Biodiversidade) (2008) Plano de Manejo: Parque Nacional da Tijuca. Ministério do Meio Ambiente, Brasília, Brazil.

IshiI, Y. \& Shimada, M. (2010) The effect of learning and search images on predator-prey interactions. Population Ecology, 52, 27-35. 
IUCN/SSC (2013) Guidelines for Reintroductions and other Conservation Translocations. IUCN/Species Survival Commission Reintroduction Specialist Group, Gland, Switzerland.

Jansen, P.A., Hirsch, B.T., Emsens, W-J., Zamora-Gutierrez, V., WiKelski, M. \& KAYs, R. (2012) Thieving rodents as substitute dispersers of megafaunal seeds. Proceedings of the National Academy of Sciences of the United States of America, 109, 1261012615.

JANZEN, D.H. (1970) Herbivores and the number of tree species in tropical forests. American Naturalist, 104, 501-528.

Jule, K.R., Leaver, L.A. \& LeA, S.E.G. (2008) The effects of captive experience on reintroduction survival in carnivores: a review and analysis. Biological Conservation, 141, 355-363.

Lipsey, M.K. \& Child, M.F. (2007) Combining the fields of reintroduction biology and restoration ecology. Conservation Biology, 21, 1387-1390.

McClintock, B.T. \& White, G.C. (2009) A less field-intensive robust design for estimating demographic parameters with markresight data. Ecology, 90, 313-320.

Molinari-Jobin, A., Marboutin, E., Wölfl, S., Wölfl, M., Molinari, P., Fasel, M. et al. (2010) Recovery of the Alpine lynx Lynx lynx metapopulation. Oryx, 44, 267-275.

Nichols, J.D. \& Armstrong, D.P. (2012) Monitoring for reintroductions. In Reintroduction Biology: Integrating Science and Management (eds J.G. Ewen, D.P. Armstrong, K.A. Parker \& P. J. Seddon), pp. 223-255. Wiley-Blackwell, Oxford, UK.

Oliveira-Santos, L.G.R. \& Fernandez, F.A.S. (2010) Pleistocene rewilding, Frankenstein ecosystems, and an alternative conservation agenda. Conservation Biology, 24, 4-5.

Ostermann, S.D., Deforge, J.R. \& Edge, W.D. (2001) Captive breeding and reintroduction evaluation criteria: a case study of peninsular bighorn sheep. Conservation Biology, 15, 749-760.

PÁDUA, J.A. (2002) Um sopro de destruição: pensamento político e crítica ambiental no Brasil escravista, 1786-1888. Zahar, Rio de Janeiro, Brazil.

Pires, A.S. \& Galetti, M. (2012) The agouti Dasyprocta leporina (Rodentia: Dasyproctidae) as seed disperser of the palm Astrocaryum aculeatissimum. Mastozoología Neotropical, 19, 147-153.

Polak, T. \& Saltz, D. (2011) Reintroduction as an ecosystem restoration technique. Conservation Biology, 25, 424.

R Development Core Team (2016) R: A Language and Environment for Statistical Computing. R Foundation for Statistical Computing. Vienna, Austria.

Reis, N.R., Peracchi, A.L., Pedro, W.A. \& Lima, I.P. (2006) Mamíferos do Brasil. Universidade Estadual de Londrina, Londrina, Brazil.

Reynolds, M.H., Hatfield, J.S., Laniawe, L.P., Vekasy, M.S., Klavitter, J.L., Berkowitz, P. et al. (2012) Influence of space use on fitness and the reintroduction success of the Laysan teal. Animal Conservation, 15, 305-317.
SARRAZIN, F. (2007) Introductory remarks: a demographic frame for reintroductions. Ecoscience, 144, iv-v.

Schaub, M., Zink, R., Beissmann, H., Sarrazin, F. \& Arlettaz, R. (2009) When to end releases in reintroduction programmes: demographic rates and population viability analysis of bearded vultures in the Alps. Journal of Applied Ecology, 46, 92-100.

Seddon, P.J., Griffiths, C.J., Soorae, P.S. \& Armstrong, D.P. (2014) Reversing defaunation: restoring species in a changing world. Science, 345, 406-412.

Silvius, K.M. \& Fragoso, J.M.V. (2003) Red-rumped agouti (Dasyprocta leporina) home range use in an Amazonian forest: implications for the aggregated distribution of forest trees. Biotropica, 35, 74-83.

Smythe, N. (1978) The natural history of the Central American agouti. Smithsonian Contributions to Zoology, 257, 1-52.

Tavecchia, G., Viedma, C., Martínez-Abraín, A., Bartolomé, M.A., Gómez, J.A. \& Oro, D. (2009) Maximizing re-introduction success: assessing the immediate cost of release in a threatened waterfowl. Biological Conservation, 142, 3005-3012.

Taylor, S.S., Jamieson, I.G. \& Armstrong, D.P. (2005) Successful island reintroductions of New Zealand robins and saddlebacks with small numbers of founders. Animal Conservation, 8, 415-420.

Varty, N. \& Guadagnin, D.L. (1998) Vouacapoua Americana. The IUCN Red List of Threatened Species 1998: e.T33918A9820054. Https://doi.org/10.2305/IUCN.UK.1998.RLTS.T33918A9820054.en [accessed 21 November 2016].

White, G.C. \& Burnham, K.P. (1999) Program MARK: survival estimation from populations of marked animals. Bird Study, 46 (Supplement), 120-138.

Williams, B.K., Nichols, J.D. \& Conroy, M.J. (2002) Analysis and Management of Animal Populations: Modeling, Estimation and Decision Making. Academic Press, San Diego, USA.

Zucaratto, R. (2013) Os frutos que as cutias comiam: recrutamento da palmeira Astrocaryum aculeatissimum na ausência de seu principal dispersor de sementes. MSc thesis. Universidade Federal Rural do Rio de Janeiro, Seropédica, Brazil.

\section{Biographical sketches}

Caio Fittipaldi Kenup has worked on the reintroduction of the red-rumped agouti in Tijuca National Park since 2011. He is interested in wildlife management, population modelling and reintroduction biology. Raíssa Sepulvida Alves is interested in wildlife management, conservation and restoring ecological interactions. CA TH A RINA KREISCHER works on the population ecology of the paca and is interested in environmental conservation and reintroduction of fauna. Fernando Fernandez is a population ecologist who has turned his interests to the conservation and management of populations, paleoecology (late Quaternary extinctions) and fostering public understanding of these subjects. 